\title{
บusisersaly
}

\section{A charge neutral, size tuneable polymersome capable of high biological encapsulation efficiency and cell permeation.}

Martin, C., Dolmazon, E., Moylan, K., Fowley, C., McHale, AP., Callan, J. F., \& Callan, B. (2015). A charge neutral, size tuneable polymersome capable of high biological encapsulation efficiency and cell permeation. International Journal of Pharmaceutics, 481, 1-8.

Link to publication record in Ulster University Research Portal

\section{Published in:}

International Journal of Pharmaceutics

Publication Status:

Published (in print/issue): 01/01/2015

\section{Document Version}

Publisher's PDF, also known as Version of record

\section{General rights}

Copyright for the publications made accessible via Ulster University's Research Portal is retained by the author(s) and / or other copyright owners and it is a condition of accessing these publications that users recognise and abide by the legal requirements associated with these rights.

\section{Take down policy}

The Research Portal is Ulster University's institutional repository that provides access to Ulster's research outputs. Every effort has been made to ensure that content in the Research Portal does not infringe any person's rights, or applicable UK laws. If you discover content in the Research Portal that you believe breaches copyright or violates any law, please contact pure-support@ulster.ac.uk. 


\title{
A charge neutral, size tuneable polymersome capable of high biological encapsulation efficiency and cell permeation
}

\author{
Chloe Martin, Elsa Dolmazon, Katrina Moylan, Colin Fowley, Anthony P. McHale, \\ John F. Callan, Bridgeen Callan*
}

School of Pharmacy and Pharmaceutical Sciences, The University of Ulster, Northern Ireland BT52 1SA, United Kingdom

\section{A R T I C L E I N F O}

\section{Article history:}

Received 3 November 2014

Received in revised form 19 December 2014

Accepted 26 December 2014

Available online 12 January 2015

\section{Keywords:}

Drug delivery

Drug release

Fluorescence

Hydrophilicity

Polymersome

Polymerisation

\begin{abstract}
A B S T R A C T
The field of therapeutics is evolving to include a greater proportion of higher molecular weight, hydrophilic biological compounds. To cater for this new era in healthcare the concomitant development of appropriate drug delivery systems is essential to aid cellular permeation. In this manuscript we present the synthesis, characterisation and biological evaluation of a charge neutral polymersome (Ps) based drug delivery system (DDS) using an amphiphilic pegylated random copolymer. A detailed dynamic light scattering study revealed that the hydrodynamic diameter of the Ps can be tailored to a specific size simply by varying the quantities and ratios used during the preparation step. The zeta potential of this new drug delivery system was determined to be $-0.095 \pm 0.037 \mathrm{mV}$, the encapsulation efficiency of Fitc-CM-Dextran (4 KDa) was 70\%, the uptake of Fitc-CM-Dextran by Hela cells was increased 4 -fold when encapsulated within the polymersomal system. The facile preparation, high loading capacity and size tuneable nature of this Ps renders it a promising alternative to the ever growing array of currently available Ps.
\end{abstract}

(c) 2015 Elsevier B.V. All rights reserved.

\section{Introduction}

Medicine has evolved from the 'one size fits all' approach to drug development with thanks in part to the Human Genome Project (HGP) that was completed more than a decade ago (Consortium, 2001). Since the completion of this landmark discovery there has been a pervasive increase and exploration of personalised medicine. The therapeutic use of siRNAs, proteins and enzymes has allowed for a revolution in healthcare regimes (Guo et al., 2010). In order to reach its full potential, it is essential that these therapeutics can be delivered to the required site of action. These large, hydrophilic and often highly charged compounds come with their own problems regarding cell permeability and drug delivery. One method that has proven successful for the delivery of these biological compounds is the use of nanoparticles (NPs). NPs are colloidal nano-sized particles with a diameter ranging between 1 and $1000 \mathrm{~nm}$ whereby the drug of interest can either be encapsulated, absorbed or dispersed within them (Allen and Cullis, 2013; Mazak and Noszal, 2014; Vonarbourg et al., 2006). Nanoparticulate systems show promise as active vectors due to

\footnotetext{
* Corresponding author. Tel.: +44 2870 123510; fax: +44 2870123518.

E-mail address: b.callan@ulster.ac.uk (B. Callan).
}

their capacity to release drugs, subcellular size allowing for relatively high intracellular uptake, the potential to provide improved stability of active substances and their biocompatibility with tissues and cells (Mora-Huertas et al., 2010). A wide variety of nanoparticles composed of a range of materials have been developed, resulting in delivery systems that vary in their physicochemical properties and thus their applications (Burt and Letchford, 2007). Current nanoparticulate drug delivery systems being investigated include liposomes (Qu et al., 2014), micelles (Torchilin, 2007), nanospheres (Yu et al., 2014), nanocapsules (Musyanovych and Landfester, 2014), niosomes (Kazi et al., 2010) and polymersomes (Wang et al., 2014; Discher et al., 1999; Levine et al., 2008; Ahmed et al., 2006) among others.

Currently there are several liposomal based drug delivery systems approved by the U.S. food and drug administration. Although these formulations show enhanced delivery and efficacy of therapy, they still have been shown to render some serious side effects (Nahire et al., 2014), partially due to their surface charges (Barenholz, 2012). To that end we have developed a polymersomal based drug delivery system that is charge neutral and whose hydrodynamic diameter can be tailored according to the desired size of the nanoparticle required.

Polymersomes are polymeric capsules with a bilayered membrane comprised of synthetic amphiphilic block copolymers, 


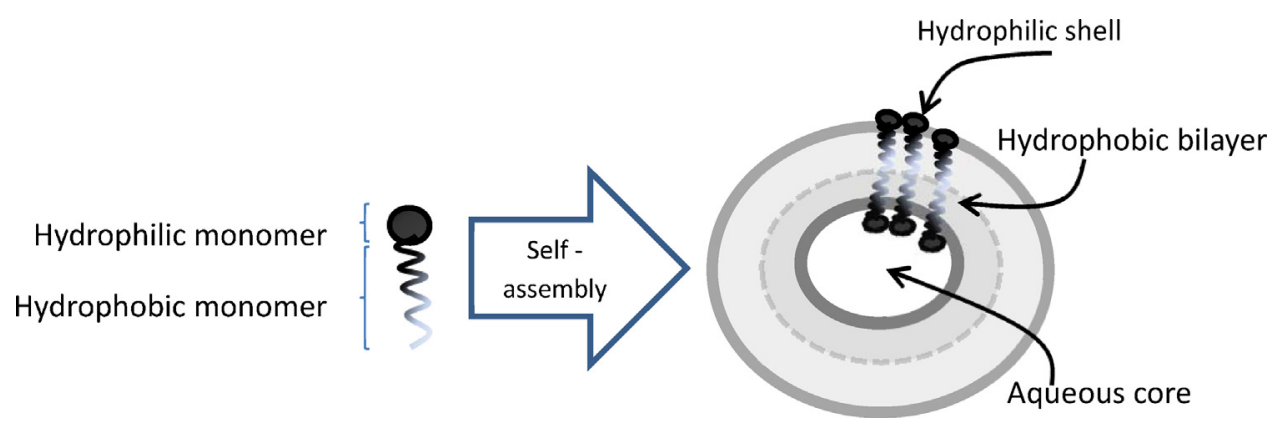

Fig. 1. Schematic representation of polymersome formed from amphiphilic co polymer.

Fig. 1. Their macromolecular structure is similar to that of the liposome in that they are both composed of a bilayer of amphiphiles enclosing an aqueous compartment (Brinkhuis et al., 2011). However, the difference between these two vehicles is that most liposomes are naturally occurring phospholipids and as such have both a strong negative charge and lower molecular weight than the synthetic polymeric alternatives. This enhanced ability to specifically tailor Ps formulation methods, physicochemical properties, release mechanisms and even targeting chemistries make polymersomes an ideal platform for the encapsulation of a broad range of therapeutic molecules (Christian et al., 2009). The incorporation of poly(ethylene glycol) (PEG) as the hydrophilic component in many of these polymersomal NPs is commonplace as it has been shown to reduce the reticuloendothelial system (RES) uptake as well as to increase the circulation time of the NP (Jokerst et al., 2011). Here we present for the first time a neutral, size tuneable Ps prepared from a co-polymer we have previously shown to self-assemble and form a micellar structure capable of encapsulating hydrophobic drugs and successfully permeate cell membranes (Yildiz et al., 2011). The random co-polymer consists of hydrophilic (PEG) and hydrophobic counterparts (decyl chain) (Scheme 1). We have formulated this neutral co-polymer into a polymersomal drug delivery system (Ps DDS) capable of encapsulating Fitc-CM-Dextran (MW $4 \mathrm{KDa}$ ) with high efficiency as well as having the ability to 'fine tune' the diameter of the vehicle as required. Fitc-CM-Dextran has been utilised as a surrogate for siRNA as it is an anionic fluorescent dextran that can be used as a biological mimic, due to its high molecular weight and hydrophilicity. When tested in Hela cells the Ps showed a 4-fold increase in uptake of Fitc-CM-Dextran compared to cells treated with Fitc-CM-Dextran alone.

\section{Materials and methods}

\subsection{Materials and reagents}

Chemicals were purchased from commercial sources at the highest possible purity and used as received. Poly(ethylene glycol)

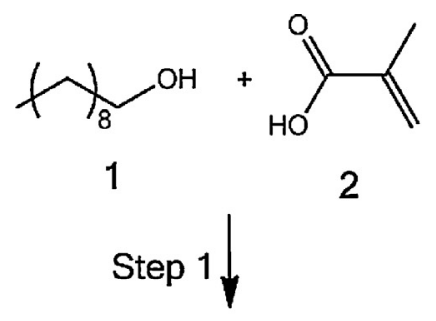

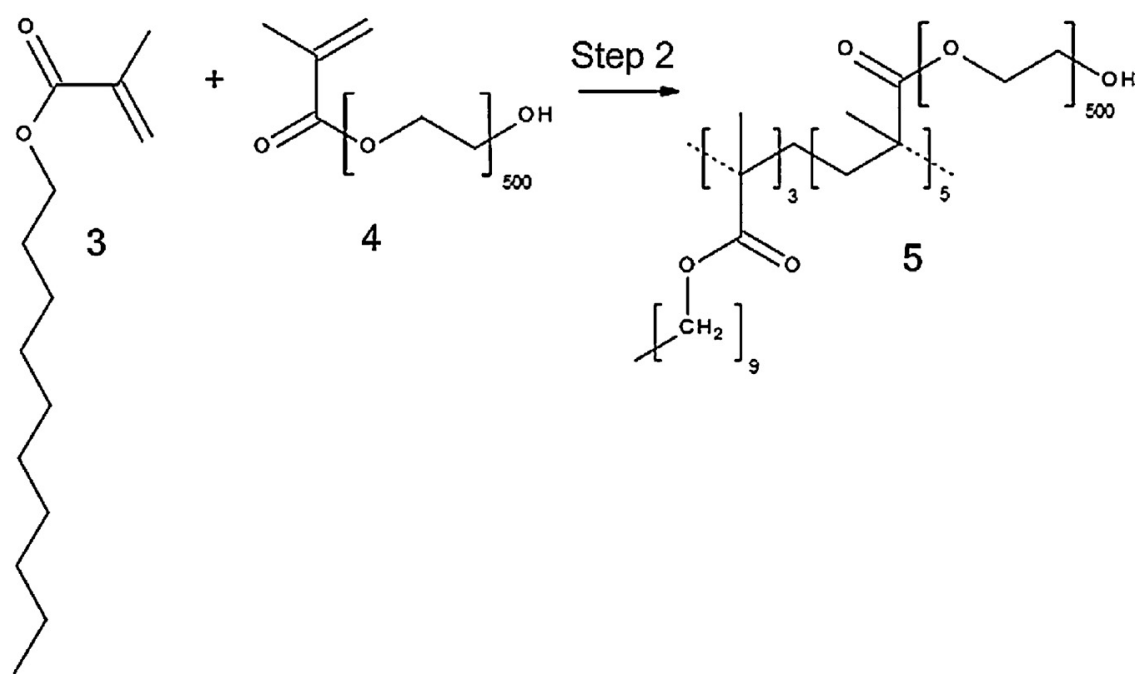

Scheme 1. Synthesis of monomer $\mathbf{3}$ (step 1) and production of co polymer $\mathbf{5}$ (step 2). 


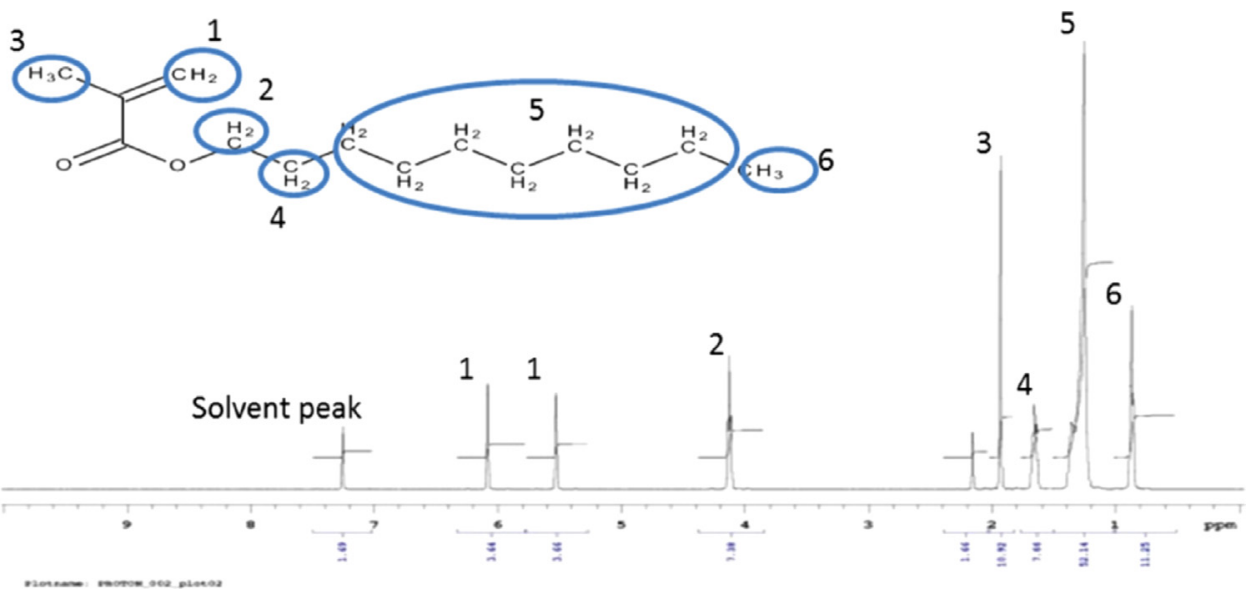

Fig. 2. ${ }^{1} \mathrm{H}$ NMR spectra of decyl methacrylate monomer $\mathbf{3}$ (shown in inset) in deuterated chloroform.

methacrylate (Mn 500 Da), fluorescein isothiocyanate-carboxymethyl-dextran (Fitc-CM-Dextran) (Mn $4 \mathrm{KDa}$ ), methacrylic acid (99\%) and 1-decanol (99\%) were purchased form Sigma-Aldrich.

\subsection{Synthesis of monomer 3}

Monomer 3 was synthesised following a previously published method (Yildiz et al., 2011). Briefly a solution of $\mathrm{N}$ - $\mathrm{N}$-dicyclohexylcarbodiimide (DCC) $(4.6 \mathrm{~g}, 22 \mathrm{mmol})$ in dichloromethane $\left(\mathrm{CH}_{2} \mathrm{Cl}_{2}\right)(20 \mathrm{ml})$ was added drop wise over 20 min to a solution of 1-decanol (1)(3 g, $19 \mathrm{mmol}), 4$-dimethylaminopyridine (DMAP) $(464 \mathrm{mg}, 3.8 \mathrm{mmol})$ and methacrylic acid $(2)(1.6 \mathrm{~g}, 18.6 \mathrm{mmol})$ in $\mathrm{CH}_{2} \mathrm{Cl}_{2}(60 \mathrm{ml})$. The reaction was maintained at $0{ }^{\circ} \mathrm{C}$ for $24 \mathrm{~h}$ under nitrogen. The resulting precipitate was filtered and dried under reduced pressure. The residue was purified by column chromatography; chloroform: methanol (19:1). The methacrylate monomer (3) was collected as a colourless oil with a slight yellowy tinge $(2.5 \mathrm{~g}, 59.4 \%)$.

\subsection{Synthesis of co-polymer $\mathbf{5}$}

Methacrylate monomer (292 mg, $1.3 \mathrm{mmol})(3)$ and poly(ethylene glycol) methacrylate $(500)(1 \mathrm{~g}, 2 \mathrm{mmol})(4)$ were added to the reaction vessel in a ratio of (3:5), along with $5 \mathrm{mg}(0.03 \mathrm{mmol})$ of free radical generator AIBN and dissolved in a minimal amount of dry tetrahydrofuran (THF). After three consecutive freeze-pumpthaw cycles the reaction vessel was sealed under vacuum at $80^{\circ} \mathrm{C}$ for $72 \mathrm{~h}$. THF $(20 \mathrm{ml})$ and hexane $(20 \mathrm{ml})$ were added and the contents centrifuged 3 times at $6000 \mathrm{rpm}$ for $5 \mathrm{~min}$ and the supernatant discarded.

The resulting pellet was dried under reduced pressure by solvent evaporation to leave amphiphilic co-polymer $\mathbf{5}$ as an oil.

\subsection{Preparation of polymersome (Ps)}

Polymersomes were prepared by creating a thin film with $1.0 \mathrm{mg}$ co polymer 5 (phase 1 ) and adding $100 \mu \mathrm{l} 2.5 \mathrm{mg} / \mathrm{ml}$ Fitc-CM-Dextran in phosphate buffered saline (PBS). The mixture was evaporated to dryness, purged with compressed air for $30 \mathrm{~s}$, before being suspended in $1.5 \mathrm{ml}$ dry chloroform. A further $2 \mathrm{ml} 1.25 \mathrm{mg} / \mathrm{ml}$ polymer in PBS (phase 2) was added and the solution sonicated using a Branson 3510 bath sonicator $(230 \mathrm{~V})$ at room temperature for $2 \mathrm{~min}$. The organic solvent was removed from the emulsion under reduced pressure at $40^{\circ} \mathrm{C}$. The polymersomes were lyophilised and stored for use when required.

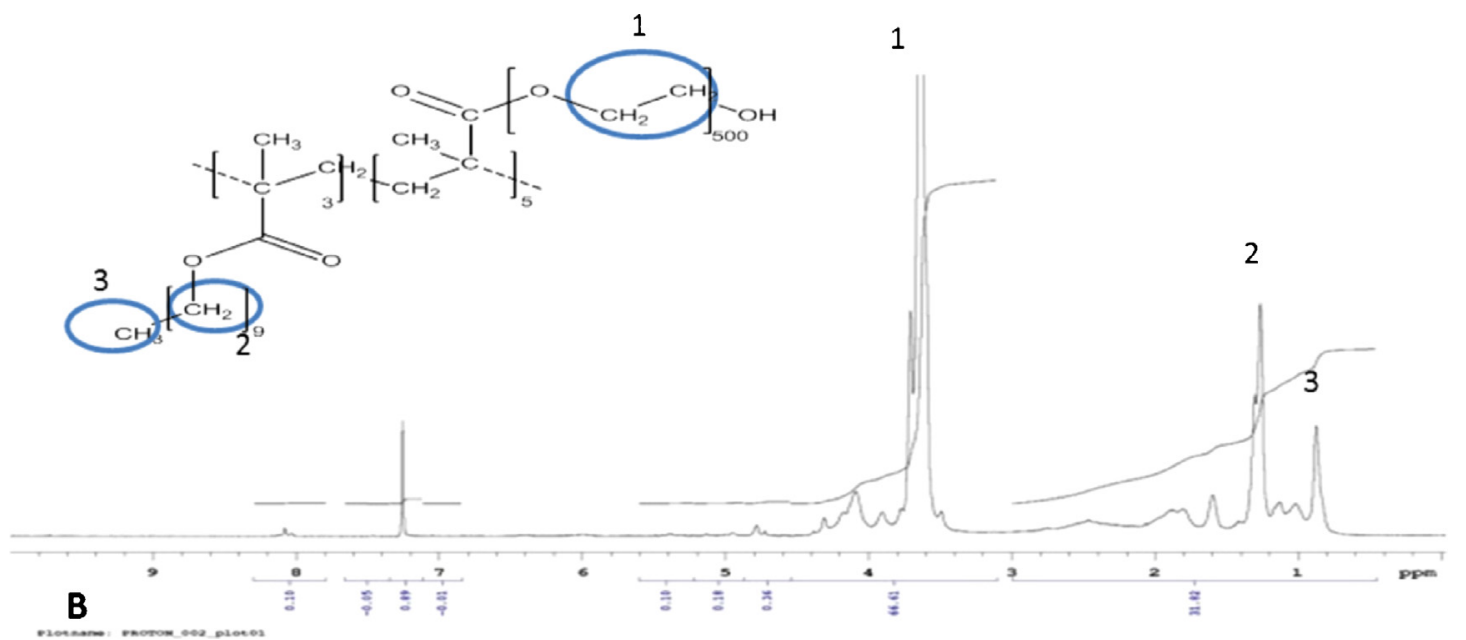

Fig. 3. ${ }^{1} \mathrm{H}$ NMR spectra of polymer $\mathbf{5}$ (shown in inset) in deuterated chloroform. 
Table 1

Integration of specified peaks in Fig. 2.

\begin{tabular}{lcl}
\hline Spectral position $(\mathrm{ppm})$ & Integration & Assigned $\mathrm{H}$ \\
\hline 0.9 & 11.25 & 5 \\
$1.20-1.35$ & 52.14 & 5 \\
$1.60-1.70$ & 7.66 & 4 \\
1.95 & 1.92 & 3 \\
4.15 & 7.38 & 2 \\
5.5 & 3.66 & 1 \\
6.1 & 3.61 & 1 \\
\hline
\end{tabular}

Table 2

Integration of specified peaks in Fig. 3.

\begin{tabular}{lcl}
\hline Spectral position $(\mathrm{ppm})$ & Integration & Assigned $\mathrm{H}$ \\
\hline $0.8-0.9$ & 6.39 & 3 \\
$1.20-1.4$ & 10.72 & 2 \\
$3.45-3.95$ & 42.99 & 1 \\
\hline
\end{tabular}

\subsection{Characterisation}

\subsubsection{Nuclear magnetic resonance (NMR)}

${ }^{1} \mathrm{H}$ NMR spectroscopy was carried out on both the synthesised monomer $\mathbf{3}$ and the copolymer 5. Samples were prepared using $10 \mathrm{mg}$ of sample dissolved in $1 \mathrm{ml}$ of deuterated chloroform and analysed using a Varian $500 \mathrm{MHz}$ instrument.

\subsubsection{Fourier transform infrared (FTIR)}

FTIR was carried out on the synthesised polymer. Samples were prepared by creating a thin film of the polymer between two glass discs. Spectra were collected on a Perkin Elmer Spectrum RX1 spectrometer.

\subsubsection{Scanning electron microscopy (SEM)}

SEM images were carried out by applying a small amount of the polymersome onto an aluminium stub. The sample was then lyophilised for $5 \mathrm{~h}$ before being sputter coated with gold and palladium. The images were recorded using a FEI Quanta SEM under a high vacuum in secondary electron mode.

\subsubsection{Encapsulation efficiency}

Encapsulation efficiency was determined by preparing polymersomes by the method described above and varying the amount of Fitc-CM-Dextran ( $4 \mathrm{KDa}$ ) available for encapsulation. $10 \mathrm{ml}$ samples of the Ps containing varying amounts of Fitc-CM-Dextran were then dialysed in $500 \mathrm{ml}$ PBS overnight using a semipermeable membrane (MWCO 12-14 KDa). The samples were analysed using a Varian Cary Eclipse fluorescence spectrometer using $1 \mathrm{~cm}$ quartz cells with an excitation wavelength of $490 \mathrm{~nm}$, slit width of $5 \mathrm{~nm}$ and collecting the emission between 520 and $620 \mathrm{~nm}$. A standard calibration graph was prepared with the equation of the line:

$y=22020 x$

where $y=$ spectral area between 510 and $700 \mathrm{~nm}$ and $x=$ concentration of Fitc-CM-Dextran $(\mu \mathrm{M})$.

The \% encapsulation efficiency was determined from the following equation:

$\frac{\mathrm{FD}_{\text {Intensity }}}{\mathrm{FO}_{\text {intensity }}} \times 100 \%$

where $\mathrm{FD}=$ fluorescence intensity of Fitc-CM-Dextran following $18 \mathrm{~h}$ dialysis and $\mathrm{FI}=$ fluorescence intensity of Fitc-CM-Dextran added.

\subsubsection{Drug release study}

Release experiments were conducted using the dialysis tubing method; briefly a $5 \mathrm{ml}$ suspension of polymersome containing $0.1875 \mathrm{mg}(46.9 \mathrm{nmol})$ Fitc-CM-Dextran was sealed in a semipermeable membrane (MWCO 12-14kDa). The tubing was immersed in $200 \mathrm{ml}$ PBS solution at $\mathrm{pH} 7.4$, with stirring. Samples were removed at $0,0.5,1,1.5,2,2.5,3,3.5$ and $4 \mathrm{~h}$ with all samples being replaced back into the buffer solution. The amount of Fitc-CM-Dextran released was analysed using a Varian Eclipse fluorescent spectrometer using a $1 \mathrm{~cm}$ quartz cell, with fluorescence measured between wavelengths of $520-620 \mathrm{~nm}$. The concentration of Fitc-CM-Dextran $(\mu \mathrm{g})$ present in solution was analysed from the standard curve equation above, and the \% release determined using the original amount of Fitc-CM-Dextran added to the dialysis bag.

\subsubsection{Cytotoxicity study}

Hela cells were seeded at a density of $5 \times 10^{4}$ cells $/ \mathrm{ml}(100 \mu \mathrm{l})$ per well into a 96 well and incubated at $37{ }^{\circ} \mathrm{C}, 5 \% \mathrm{CO}_{2}, 20 \% \mathrm{O}_{2}$ overnight using Hams-F12 supplemented media. Following adherence, fresh media was applied to each well $(160 \mu \mathrm{l})$ with varying concentrations of polymersome in $40 \mu \mathrm{l}$ sterile PBS. The cells were then incubated for a further $24 \mathrm{~h}$ before being washed twice with PBS, treated with MTT solution ( $5 \mathrm{mg} / \mathrm{ml}$ serum free media) and incubated for $3 \mathrm{~h}$. The purple blue formazan crystals were dissolved by the addition of dimethylsulfoxide (DMSO) and the absorbance read at $570 \mathrm{~nm}$ using a BMG labtech Omega microplate.

\subsubsection{Dynamic light scattering (DLS), polydispersity index (PDI) and zeta potential (ZP) \\ The polymersome solutions were suitably diluted to analyse the particle size distribution and polydispersity index using dynamic light scattering (DLS) method. The samples were diluted using sterile PBS and all measurements taken at room temperature on a Malvern Nano-ZS zetasizer. The hydrodynamic diameter is quoted as size \pm standard error of the mean $(n=3)$. The polydispersity index is quoted as $\mathrm{PDI} \pm$ standard deviation $(n=3)$. The zeta}
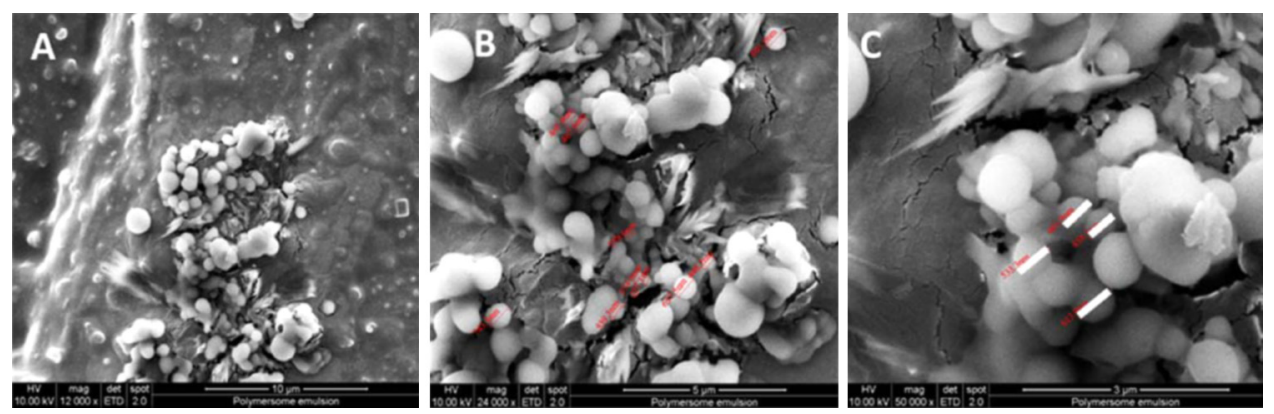

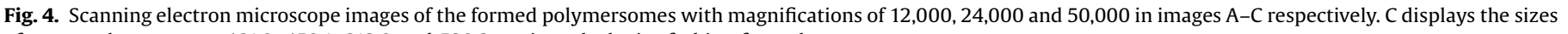
of some polymersomes $461.9,458.1,613.9$ and $538.3 \mathrm{~nm}$ in a clockwise fashion from the top. 


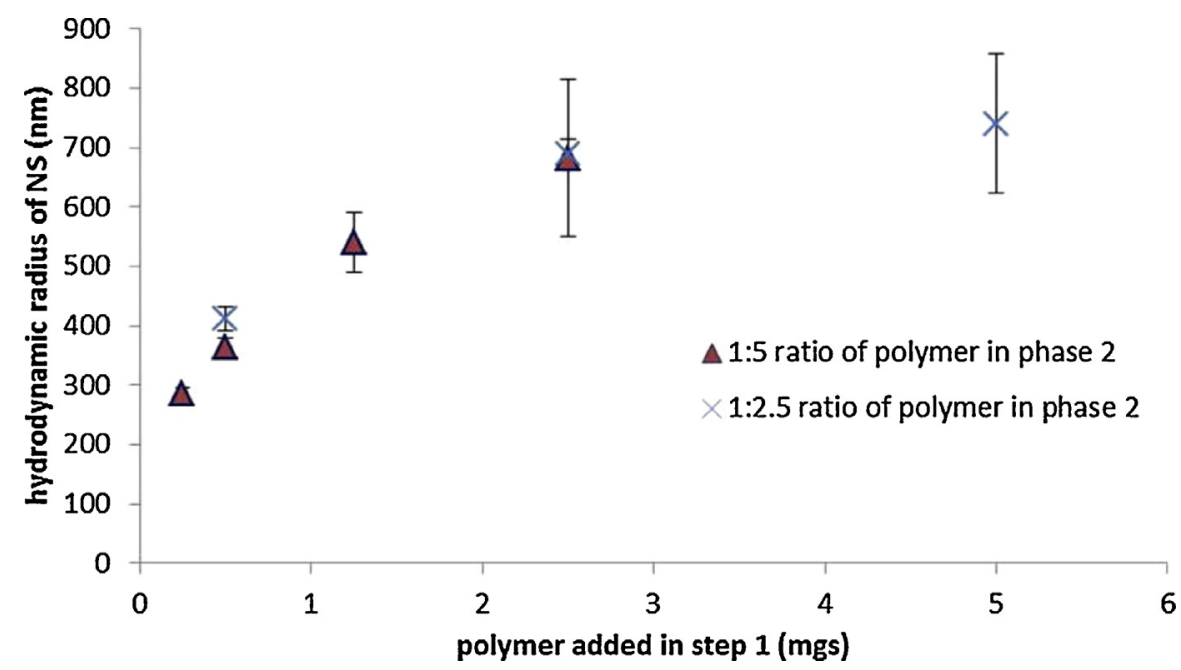

Fig. 5. Hydrodynamic diameter with varying amounts of co-polymer used in formulation steps.

potential was measured using the same instrument at room temperature in PBS using disposable folded capillary cells and quoted as $\mathrm{ZP} \pm$ standard deviation $(n=3)$.

\subsubsection{Bioimaging}

Hela cells were seeded at a density of $5 \times 10^{4}$ cells/ml $(500 \mu \mathrm{l})$ onto a $2 \mathrm{~cm}^{2}$ glass cover slip and incubated at $37^{\circ} \mathrm{C}, 5 \% \mathrm{CO}_{2}, 20 \% \mathrm{O}_{2}$ overnight using Hams-F12 supplemented media. Following adherence, fresh media was applied to the cells $(400 \mu \mathrm{l})$ and either $20 \mu \mathrm{l} 2.5 \mathrm{mg} / \mathrm{ml}$ Fitc-CM-Dextran (4 KDa) and $80 \mu \mathrm{l}$ PBS (control) or $100 \mu \mathrm{l}$ Liposome containing $0.05 \mathrm{mg}$ Fitc-Dextran ( $4 \mathrm{KDa})$ in PBS. The cells were incubated in the environment described for a further $5.5 \mathrm{~h}$ before being washed twice with $1 \mathrm{ml}$ PBS and imaged using a Leica SP5Confocal Microscope with an excitation wavelength of $488 \mathrm{~nm}$ and emission collected between 510 and $620 \mathrm{~nm}$.

\subsubsection{In-vitro quantification study}

Hela cells were seeded at a density of $5 \times 10^{4}$ cells $/ \mathrm{ml}(100 \mu \mathrm{l})$ per well into a 96 well and incubated at $37^{\circ} \mathrm{C}, 5 \% \mathrm{CO}_{2}, 20 \% \mathrm{O}_{2}$ overnight using Hams-F12 supplemented media. Following adherence, fresh media was applied to each well $(160 \mu \mathrm{l})$ with either $8 \mu \mathrm{l} 2.5 \mathrm{mg} / \mathrm{ml}$ Fitc-CM-Dextran and $32 \mu \mathrm{l}$ PBS or $40 \mu \mathrm{l}$ Ps containing $0.02 \mathrm{mg}$ Fitc-dextran with the control cells containing $160 \mu \mathrm{l}$ media and $40 \mu \mathrm{l} \mathrm{PBS}$. The cells were then incubated in the conditions described for a further $5.5 \mathrm{~h}$ before being washing twice with PBS and the emission read using a BMG labtech Omega microplate with an excitation wavelength of 485 and emission collected at $520 \mathrm{~nm}$.

\section{Results and discussion}

The synthesis of monomer $\mathbf{3}$ and co-polymer $\mathbf{5}$ were prepared as previously described (Yildiz et al., 2011) and the structures confirmed by ${ }^{1} \mathrm{H}$ NMR spectroscopy (Figs. 2 and 3, respectively). The following chemical shifts were identified for monomer $\mathbf{3}$, as listed with integrations in Table $1,:{ }^{1} \mathrm{H}$ NMR $\left(\mathrm{CDCl}_{3}\right): \delta=0.90(3 \mathrm{H}, \mathrm{t}$, $13 \mathrm{~Hz}), 1.20-1.35(14 \mathrm{H}, \mathrm{m}), 1.60-1.70(2 \mathrm{H}, \mathrm{m}), 1.95(3 \mathrm{H}, \mathrm{s}), 4.15(2 \mathrm{H}$, $\mathrm{t}, 13 \mathrm{~Hz}), 5.5(1 \mathrm{H}, \mathrm{s}), 6.1(1 \mathrm{H}, \mathrm{s})$ the $\mathrm{m} / \mathrm{z}$ peak was found to be 228 which corresponds to $M+1$. The corresponding chemical shifts for the protons in polymer 5 were found to be: ${ }^{1} \mathrm{H}$ NMR $\left(\mathrm{CDCl}_{3}\right)$ : $\delta=0.8-0.89$ (3H, bs), 0.9-1.20 (4H, m), 1.20-1.40 (14H, m); $1.50-$ $1.60(2 \mathrm{H}, \mathrm{m}), 1.7-2.05(6 \mathrm{H}, \mathrm{m}), 3.45-3.95(42 \mathrm{H}, \mathrm{m}), 4.2-4.3(4 \mathrm{H}, \mathrm{m})$. The olefinic protons present in $\mathbf{3}$ (Fig. 2) at 5.5 and $6.1 \mathrm{ppm}$ were absent in the spectrum of $\mathbf{5}$ (Fig. 3) indicating effective polymerisation between the two monomers resulting in the formation of the new carbon carbon sigma bond. The polymerisation was carried out in a 3:5 molar ratio of hydrophobic: hydrophilic monomers. This ratio is corroborated when considering the integration values of specific known monomer peaks, Table 2. From Fig. 2 we have established that the majority of the aliphatic protons of the carbon 10 chain are found between 1.2 and $1.4 \mathrm{ppm}$. In contrast to this the vast majority of protons from the poly(ethylene) glycol monomer can be found downfield between 3.45 and $3.95 \mathrm{ppm}$. If we consider the alkyl chain to have 16 attributed protons (to allow for the shielding and de-shielding effects seem from the methyl and adjacent ester groups respectively) then the polymer shown in Fig. 3 should show an integration value that can be credited to 48 protons $(16 \times 3)$ at 1.2-1.4 ppm. Similarly for the PEG monomer, if we consider that the average molecular weight of the monomer is $500 \mathrm{Da}$, this corresponds to 11 repeat units, as with the alkyl chain if we allow for the de-shielding effect seen from the first and last units, then we can attribute the integration of the peak between 3.45 and $3.95 \mathrm{ppm}$ to be as a result of 200 protons $(40 \times 5)$. The integration of the corresponding protons from both monomers is shown in Fig. 2, it corroborates well with the anticipated 40:200 proton ratio from the hydrophobic:hydrophilic monomers.

The FTIR spectra displayed the following peaks; $3473.8 \mathrm{~cm}^{-1}$ sharp peak attributed to the $\mathrm{O}-\mathrm{H}$ stretch of the alcohol group on the poly(ethylene glycol) monomer, $2919.5 \mathrm{~cm}^{-1}$ medium strong peak attributed to the alkyl $\mathrm{C}-\mathrm{H} 1726.3 \mathrm{~cm}^{-1}$ a very strong peak

Table 3

Encapsulation efficiency with \% loading of polymersome with Fitc-CM-Dextran.

\begin{tabular}{lcc}
\hline Amou1.5-1.6nt Fitc-CM-Dextran (mg) & Loading (\% wt/wt) & \% Encapsulation efficiency \\
\hline 0.125 & 3.5 & $70.3 \pm 1.2$ \\
0.25 & 6.7 & $72.2 \pm 3.7$ \\
0.375 & 9.7 & $69.6 \pm 0.1$ \\
0.5 & 12.5 & $53.0 \pm 2.9$ \\
0.75 & 17.6 & $53.2 \pm 0.3$ \\
\hline
\end{tabular}




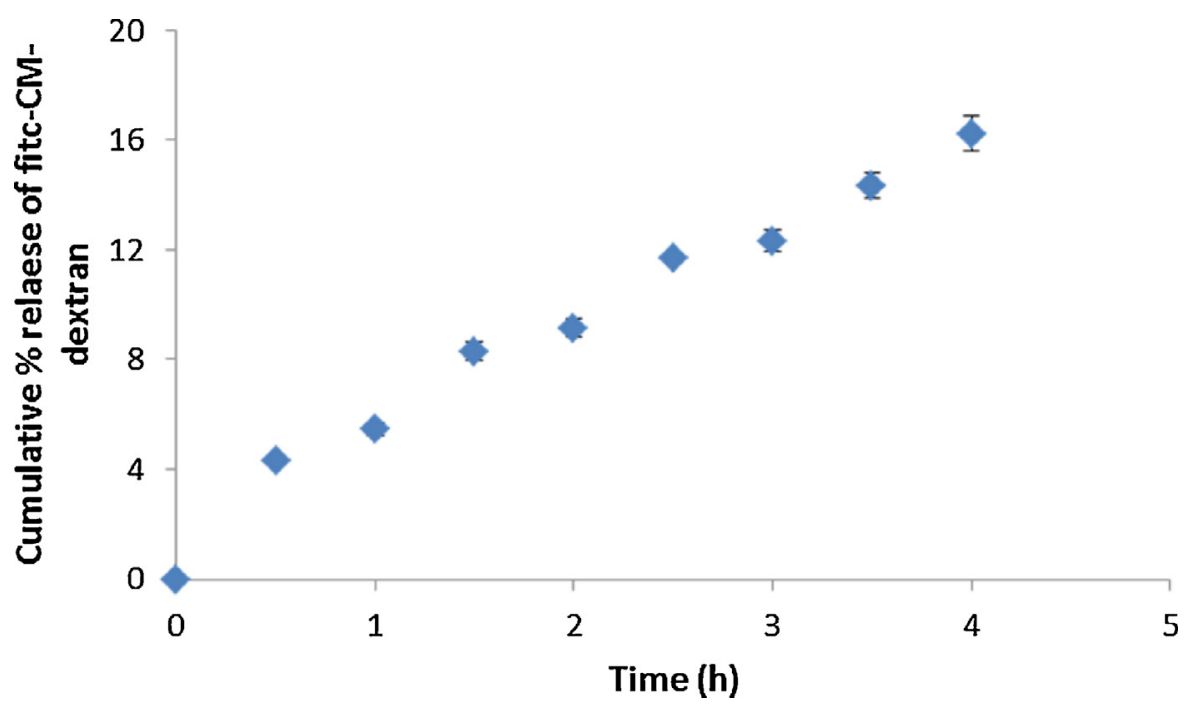

Fig. 6. Release profile of the Fitc-CM-Dextran from the polymersome encapsulated within a semi permeable membrane.

corresponding to the $\mathrm{C}=\mathrm{O}$ stretch of the ester groups; $1384.1 \mathrm{~cm}^{-1}$ a medium peak depicting a methyl group bend; $1247.8 \mathrm{~cm}^{-1}$ which is attributed to the $\mathrm{C}-\mathrm{O}$ stretch from the ester group and finally a broad strong peak is seen between 1200 and $1000 \mathrm{~cm}^{-1}$ which can be attributed to the $\mathrm{C}-\mathrm{O}$ stretch of the ether groups on the poly(ethylene glycol). As was observed from the NMR data, the spectral vibrations attributed to the $C=C$ groups is absent. The FTIR data further confirms the production of the polymer. This polymer has been used previously for the delivery of hydrophobic compounds as it spontaneously forms micellar structures with a hydrophobic core which we have shown to be both biocompatible and capable of cellular delivery (Fowley et al., 2012; Swaminathan et al., 2014).

The polymersomes were characterised for size using both DLS and SEM while surface charge was determined from zeta potential measurements. The polydisperisty index (PDI) for each polymersome was also recorded. Fig. 4a-c displays the SEM images received with magnification increasing from left to right. The spherical shape of the polymersomes was confirmed and the sizes determined from the microscope were comparable to those achieved using DLS (Fig. 5) when comparing the same amounts of polymer added in each phase (as described in Section 2.5.3). From the SEM image (Fig. 4c) the diameters of a selection of polymersomes were determined and the sizes ranged between 458 and $620 \mathrm{~nm}$. Not surprisingly this size range is significantly larger than the corresponding micelles formed from the same amphiphilic co-polymer which was in the order of $20 \mathrm{~nm}$, due to the introduction of the hydrophobic bilayer within the Ps structure. The PDI recorded for each polymersome was found to be between 0.1 and 0.5 , indicating appropriate polydispersity of the suspension. The zeta potential was determined as $-0.095 \pm 0.037 \mathrm{mV}$ indicating charge neutral polymersomes as anticipated

The encapsulation efficiency of the Ps was determined with varying amounts of Fitc-CM-Dextran, Table 3. The maximum efficiency of $72 \%$ was observed for loading at $6.67 \%$ wt:wt (wt of fluorophore:total DDS wt). The Ps was capable of incorporating larger amounts of Fitc-CM-Dextran, however when the \% loading exceeded $10 \%$ wt:wt the encapsulation efficiency dropped rather significantly to $53 \%$.

The ability of the polymersome to release its content was analysed as described in Section 2.5.5. The release profile is shown in Fig. 5. After a period of $4 \mathrm{~h}$, the polymersome had released $16 \%$ of its cargo, this experiment was not carried out under sink conditions and therefore it would be expected that under sink conditions the contents of the DDS may be released sooner, however it is clear from this study that the polymersome does indeed release its contents by osmosis.

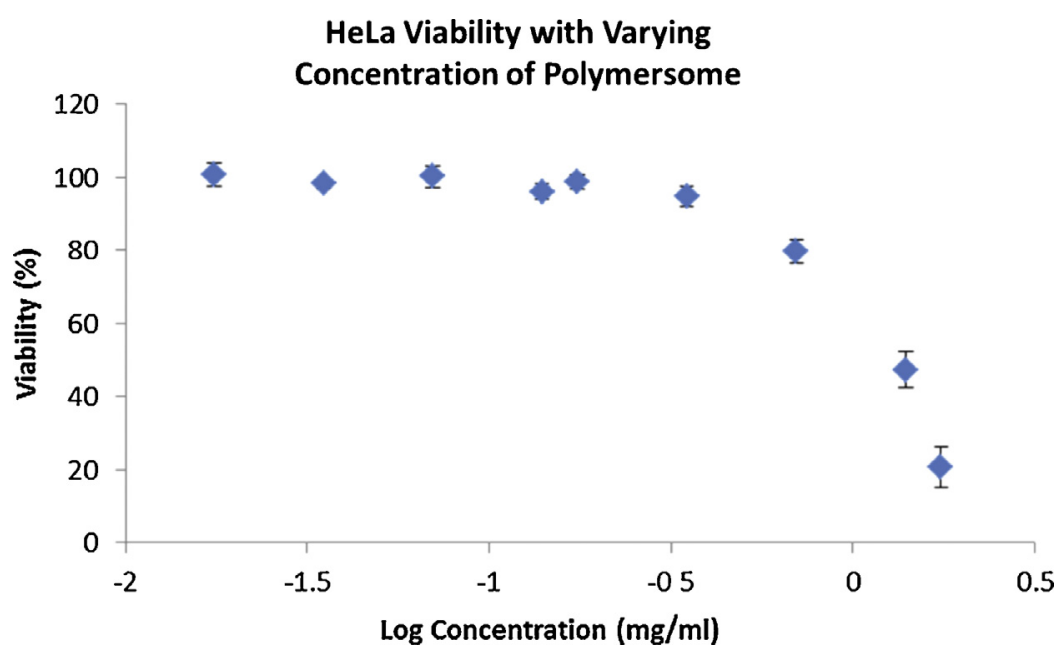

Fig. 7. MTT cell viability study with varying concentrations of polymersome incubated with Hela cells for $24 \mathrm{~h}$. 

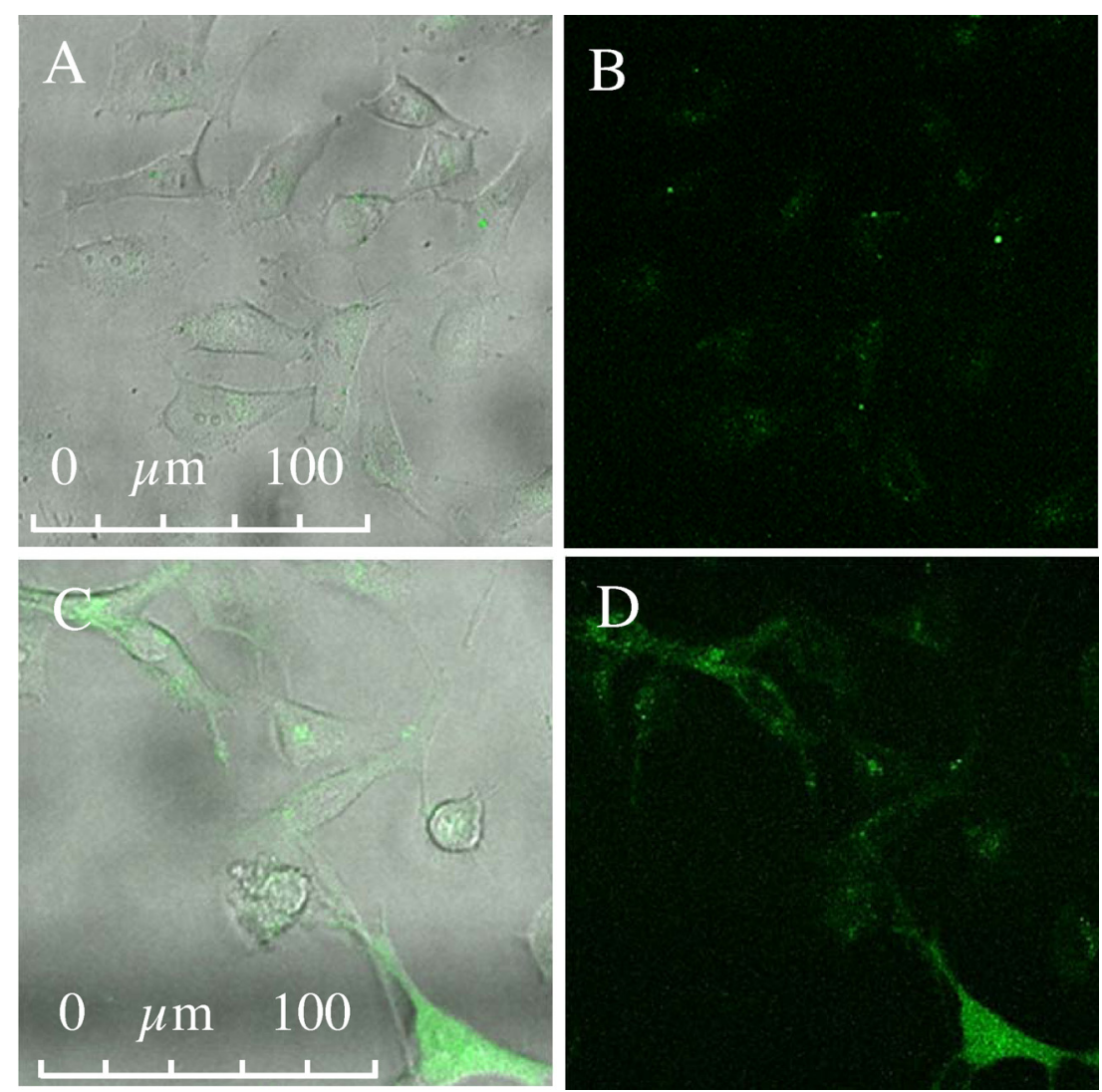

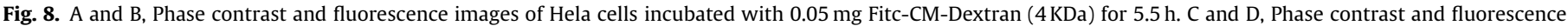
images of Hela cells incubated for $5.5 \mathrm{~h}$ with $0.05 \mathrm{mg}$ Fitc-CM-Dextran encapsulated within Ps.

The ability to vary the hydrodynamic diameter with simply varying the concentrations of polymer is shown in Fig. 6 . There are numerous examples in the literature where the size of the polymersome have been varied through the incorporation of different polymers (Nahire et al., 2014; Johnston et al., 2010). The reason for these differences is due to the variability in interdigitation of the bilayer (Battaglia and Ryan, 2005) and can be modulated by changing the nature of the hydrophobic entities in the amphiphilic polymer or the chemical environment used to produce the polymersomes (Wachtel et al., 2013). Here we reveal a significant degree of control in the size of the polymersome simply by varying the amounts of co-polymer used during production. It can be seen from Fig. 6 that by varying the amount of co-polymer added in phase 1 of the production we can control the diameter of the Ps. We have shown that by varying the amount of co-polymer added in phase 1 from $0.25 \mathrm{mg}$ to $0.5 \mathrm{mg}$, while keeping the ratio of co-polymer added in phase 2 constant at $1: 5$, an increase in diameter from $284 \mathrm{~nm}$ to $364 \mathrm{~nm}$ was observed, the PDI recorded for each is these samples was $0.36 \pm 0.01$ and $0.36 \pm 0.02$ respectively, indicting a good uniformity in polydispersity. Similarly if the amount of co-polymer added in phase 1 of the production was increased to $1.25 \mathrm{mg}$, with again a $1: 5$ ratio of co-polymer added in phase 2, the hydrodynamic diameter of the Ps increases to $539 \mathrm{~nm}$ (PDI $0.35 \pm 0.05$ ). A similar trend was evident when the Ps was prepared using a 1:2.5 ratio of co-polymer between phase 1 and 2 with the polydispersity index ranging from 0.22 to 0.28 , again indicative of good polydispersity. These results suggest that the ability to control the size of the Ps is primarily due

\section{\% Uptake by Hela Cells}

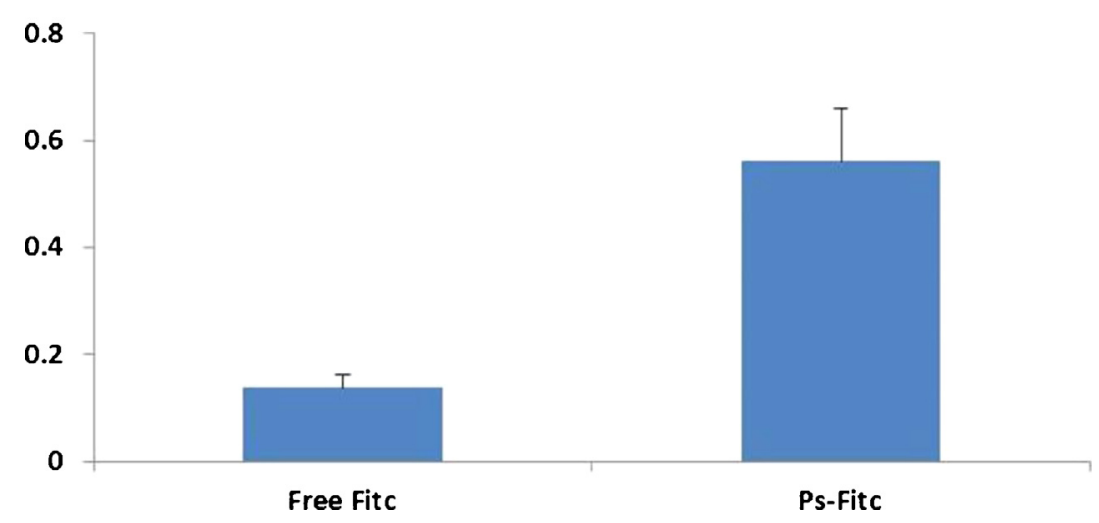

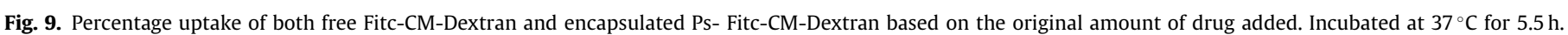


to the amount of co-polymer used in the production of the inverted micelle (phase 1). However when the amount of co-polymer added in phase 1 exceeds $2.5 \mathrm{mg} / \mathrm{ml}$ no significant increase in Ps diameter was observed.

In order to establish the biocompatibility of this new drug delivery system it was analysed for cytotoxicity in Hela cells using the MTT viability assay. The results shown in Fig. 7 reveal that the system is not toxic to Hela cells in a concentration up to $0.3 \mathrm{mg} / \mathrm{ml}$ with an approximate $\mathrm{LD}_{50}$ of $1.25 \mathrm{mg} / \mathrm{ml}$. This value was higher than that determined when the same polymer was assembled into micelles (Yildiz et al., 2011), one possible explanation for this could lie with the increased size of the Ps when compared to the micelle, however the toxicity is well within the range which would be deemed appropriate for use (Rad et al., 2014). The ability of the Ps to cross the cell membrane was investigated using the photochemical properties of the biological mimic Fitc-CMDextran by incubating either the free chromophore or the encapsulated chromophore in Hela cells. It can be seen from the confocal images displayed in Fig. 8 that the Ps encapsulated Fitc-CM-Dextran was in deed capable of crossing the cell membrane. The punctate nature of the image would suggest that the DDS is accumulating within the lysosome. There was a significant increase in the amount of fluorescence generated from the Fitc-CM-Dextran when encapsulated within the Ps when compared to the same amount of free Fitc-CM-Dextran, as evident from both the phase contrast images $A$ and $C$ and the fluorescence images B and D. Both C and D have an increased intensity of fluorescence emission when excited at $488 \mathrm{~nm}$. This enhancement was quantified using a plate reader with a 4-fold increase in the uptake of encapsulated Fitc-CM-Dextran when compared to free Fitc-CM-Dextran (Fig. 9).

\section{Conclusions}

We have successfully prepared a neutral random co-polymer capable of forming polymersomes and enhancing the delivery of a high molecular weight, negatively charged molecule. The polymersome enhanced the delivery of Fitc-CM-Dextran to Hela cells 4fold. This is the first time a co-polymer such as this has been formulated into a bilayered sytem with an aqueous core. The potential to tailor the specific size of the nanoparticle and the facile synthetic procedure to create these supramolecular structures means it could be tailored to suit various biological therapies. In the future polymersomes such as these could be further adapted to increase capacity and site specific delivery. The relatively low cellular uptake could be enhanced with the introduction of cholesterol into the bilayered system of the DDS (He et al., 2014). The addition of site specific receptors for targeting and enhanced cellular uptake could also increase cell specificity and uptake.

\section{Acknowledgements}

The authors would like to thank the University of Ulster and the Department for Employment and Learning (DEL) Northern Ireland for their financial support.

\section{References}

Ahmed, F., et al., 2006. Biodegradable polymersomes loaded with both paclitaxel and doxorubicin permeate and shrink tumors, inducing apoptosis in proportion to accumulated drug. J. Controlled Release 116, 150-158.

Allen, T.M., Cullis, P.R., 2013. Liposomal drug delivery systems: from concept to clinical applications. Adv. Drug Deliv. Rev. 65, 36-48.

Barenholz, Y., 2012. Doxil - the first FDA-approved nano-drug: lessons learned. J. Controlled Release 160, 117-134.

Battaglia, G., Ryan, A.J., 2005. Bilayers and Interdigitation in Block Copolymer Vesicles. J. Am. Chem. Soc. 127, 8757-8764.

Brinkhuis, R.P., Rutjes, F.P.J.T., van Hest, J.C.M., 2011. Polymeric vesicles in biomedical applications. Polym. Chem. 2, 1449-1462.

Burt, H., Letchford, K., 2007. A review of the formation and classification of amphiphilic block copolymer nanoparticular structures: micelles, nanospheres, nanocapsules and polymersomes. Eur. J. Pharm. Biopharm. 65, 259-269.

Christian, D.A., et al., 2009. Polymersome carriers: from self-assembly to siRNA and protein therapeutics. Eur. J. Pharm. Biopharm. 71, 463-474.

Consortium, I.H.G.S., 2001. Initial sequencing and analysis of the human genome Nature 409, 860-921.

Discher, B.M., et al., 1999. Polymersomes: tough vesicles made from diblock copolymers. Science 284, 1143-1146.

Fowley, C., et al., 2012. Highly luminescent biocompatible carbon quantum dots by encapsulation with an amphiphilic polymer. Chem. Commun. 48 , 9361-9363.

Guo, P., et al., 2010. Engineering RNA for targeted siRNA delivery and medical applications. Adv. Drug Deliv. Rev. 62, 650-666.

He, Z.-Y., et al., 2014. Recent development of poly(ethylene glycol)-cholesterol conjugates as drug delivery systems. Int. J. Pharm. 469, 168-178.

Johnston, A.H., Dalton, P.D., Newman, T.A., 2010. Polmersomes, smaller than you think: ferrocene as a TEM probe to determine core structure. J. Nanopart. Res. 12, 1997-2001.

Jokerst, J.V., Lobovkina, T., Zare, R.N., Gambhir, S.S., 2011. Nanoparticulate PEGylation for imaging and therapy. Nanomedicine 6, 715-728.

Kazi, K.M., et al., 2010. Niosome: a future of targeted drug delivery systems. J. Adv. Pharm. Technol. Res. 4, 374-380.

Levine, D.H., et al., 2008. Polymersomes: a new multi-functional tool for cancer diagnosis and therapy. Methods 46, 25-32.

Mazak, K., Noszal, B., 2014. Drug delivery: a process goverened by species-specific lipophilicities. Eur. J. Pharm. Sci. 62, 96-104.

Mora-Huertas, C., Fessi, H., Elaissari, A., 2010. Polymer-based nanocapsules for drug delivery. Int. J. Pharm. 385, 113-142.

Musyanovych, A., Landfester, K., 2014. Polymer micro- and nanocapsules as biological carriers with multi functional properties. Macromol. Biosci. 14, 458-477.

Nahire, R., et al., 2014. Multifunctional polymersomes for cytosolic delivery of gemcitabine and doxorubicin to cancer cells. Biomaterials 35 , 6482-6497.

Qu, M.-H., et al., 2014. Liposome-based co-delivery of SiRNA and docetaxel for the synergistic treatment of lung cancer. Int. J. Pharm. 474, 112-122.

Rad, I., Mobasheri, H., Najafi, F., Rezaei, M., 2014. Efficient repairing effect of PEC based tri-block copolymer on mechanically damaged PC12 cells and isolated spinal cord. J. Mater. Sci.: Mater. Med. 25, 1539-1551.

Swaminathan, S., et al., 2014. Intracellular guest exchange between dynamic supramolecular hosts. J. Am. Chem. Soc. 136, 7907-7910.

Torchilin, V., 2007. Micellar nanocarriers: pharmaceutical perspectives. Pharm. Res. $24,1-16$.

Vonarbourg, A., Passirani, C., Saulnier, P., Benoit, J.-P., 2006. Parametres influencing the stealthiness of collodial drug delivery systems. Biomaterials 27 , 4356-4373.

Wachtel, E., Bach, W., Miller, I.R., 2013. Room temperature ordering of dipalmitoylserine bilayers induced by short chain alcohols. Chem. Phys. Lipids $175,20-26$.

Wang, X., et al., 2014. Concurrent block copolymer polymersome stabilisation and bilayer permeabilisation by stimuli-regulated 'tracelesss' crosslinking. Angew. Chem. Int. Ed. 53, 3138-3142.

Yildiz, I., et al., 2011. Supramolecular strategies to construct biocompatable and photoswitable fluorescent assemblies. J. Am. Chem. Soc. 133, 871-879.

Yu, H., et al., 2014. Novel approach to extract thermally stable cellulose nanospheres with high yield. Mater. Lett. 131, 12-15. 